\title{
Effect of Closed Suction Drain on Blood Loss and Transfusion Rates in Simultaneous Bilateral Total Knee Arthroplasty: A Prospective Randomized Study
}

\author{
Anoop Jhurani, $\mathrm{MS}^{1}$, Gautam M. Shetty, $\mathrm{MS}^{2}$, Vinay Gupta, $\mathrm{MS}^{1}$, Purvi Saxena, B.Tech ${ }^{1}$, \\ and Nidhi Singh, M.Pharm ${ }^{1}$ \\ ${ }^{1}$ Department of Orthopaedics, Fortis Escorts Hospital, Jaipur; ${ }^{2}$ Department of Orthopaedics, Breach Candy Hospital, Mumbai, India
}

\begin{abstract}
Purpose: Simultaneous bilateral total knee arthroplasty (TKA) is associated with excessive blood loss and morbidity arising from postoperative reduction in hemoglobin $(\mathrm{Hb})$. The purpose of this prospective randomized study was to determine if drains have any effect on blood loss, postoperative reduction in $\mathrm{Hb}$ levels and transfusion rates compared to no drainage in simultaneous bilateral TKAs.

Materials and Methods: Two hundred and thirty patients who underwent simultaneous bilateral TKA by a single surgeon were randomly allotted to drain or no-drain group ( $\mathrm{n}=115$ in each group). Postoperative $\mathrm{Hb}$ level, blood loss volume and transfusion rate were compared between the two groups.

Results: The mean postoperative $\mathrm{Hb}$ level $(\mathrm{p}=0.38)$, blood loss volume $(\mathrm{p}=0.33)$ and transfusion rate ( $\mathrm{p}=0.52)$ in the drain group were not significantly different compared to the no-drain group. No statistical difference was found in terms of complications, readmissions and mortality rates between the two groups.

Conclusions: No significant difference was observed in the two groups with respect to blood loss and blood transfusion. Non-drainage does not offer an advantage over drainage with respect to conserving blood in simultaneous bilateral TKA.
\end{abstract}

Keywords: Knee, Arthroplasty, Bilateral, Blood loss, Transfusion, Drainage

\section{Introduction}

Drains are routinely used during closure in total knee arthroplasty (TKA) due to the traditional belief that it will prevent wound hematoma, facilitate wound healing and minimize chances of infection ${ }^{1,2}$. However, the use of drains during TKA is associated with excessive blood loss, the need for postoperative

Received October 22, 2015; Revised (1st) November 30, 2015;

(2nd) January 11, 2016; Accepted February 10, 2016

Correspondence to: Anoop Jhurani, MS

Department of Orthopaedics, Fortis Escorts Hospital, Jawaharlal Nehru Marg, Near World Trade Park, Malviya Nagar, Jaipur, Rajasthan 302017, India

Tel: +91-141-254-7000, Fax: +91-141-254-7002

E-mail: anoopjhurani@gmail.com

This is an Open Access article distributed under the terms of the Creative Commons Attribution Non-Commercial License (http://creativecommons.org/licenses/by-nc/4.0/) which permits unrestricted non-commercial use, distribution, and reproduction in any medium, provided the original work is properly cited. allogenic blood transfusion and increased complications ${ }^{3-6)}$.

Bilateral TKA involves greater blood loss compared to unilateral TKA with the average blood loss reported at over $1,200 \mathrm{~mL}$ in bilateral TKAs ${ }^{4,78}$. This blood loss and the subsequent reduction in hemoglobin $(\mathrm{Hb})$ levels may be more pronounced in patients undergoing simultaneous bilateral TKAs. Perioperative anemia due to excessive blood loss, especially in patients undergoing simultaneous bilateral TKA, may result in increased risk of postoperative infection, poor functional recovery, longer hospital stay and mortality ${ }^{9}$. However, the effect of the use of drain on blood loss, postoperative reduction in $\mathrm{Hb}$ levels and transfusion rates compared to no drainage in simultaneous bilateral TKA is unclear.

Although several studies have analyzed the use of drains and its effect on blood loss during TKA, most of them have been done in patients undergoing unilateral TKA $s^{5,6,10,11)}$. Literature is lacking regarding the effect of drain usage in patients undergoing simultaneous bilateral TKA especially in terms of blood loss 
and the need of postoperative blood transfusions. To the best of our knowledge, there are no randomized controlled trials in simultaneous bilateral TKAs that have analyzed the effect of drain on postoperative blood loss and reduction in $\mathrm{Hb}$. Hence, the purpose of this prospective randomized study was to determine if drains have any effect on blood loss, postoperative reduction in $\mathrm{Hb}$ levels and transfusion rates compared to no drainage in simultaneous bilateral TKAs.

\section{Materials and Methods}

For this prospective randomized single-surgeon study conducted from April 2013 to December 2014, all patients who underwent simultaneous bilateral TKA for knee arthritis at the study institution were eligible. Inclusion criterion for the study was all patients who were eligible for simultaneous bilateral TKA for knee arthritis due to osteoarthritis, rheumatoid arthritis or post-traumatic arthritis. The exclusion criteria included patients who opted for staged bilateral TKA, patients where simultaneous bilateral TKA could not be performed due to previous history of deep vein thrombosis (DVT) or pulmonary embolism, myocardial infarction (MI), coronary bypass graft surgery in last one year and in patients who refused to give consent for participation in the study. Of the 256 patients eligible for simultaneous bilateral TKA during the study period, 26 patients had to be excluded due to various reasons including previous history of DVT or MI $(n=3)$, option for staged TKA $(n=8)$ and refusal to give consent for par- ticipation in the study $(n=15)$. A total of 230 patients participated in the study and were randomly allocated to the two study groups with 115 patients in each group (Fig. 1). The study was done in hospital setting and was approved by the institutional ethics committee. The CONSORT (consolidated standards of reporting trials) guidelines ${ }^{12)}$ were followed throughout the study for its conduction and reporting and an informed consent was taken from all patients who participated in the study.

Our primary objective was to compare the amount of blood loss, postoperative $\mathrm{Hb}$ levels and transfusion rates in patients undergoing simultaneous bilateral TKA with either closed suction drains or no drains. Hence, the study population was randomized into two groups: drains and no drains (Fig. 1) based on sequentially numbered sealed envelopes containing random cards named as "drain group" and "no-drain group". Random number table method was used for sequence generation. The allocated envelope for each patient was opened by the staff nurse in the operation theatre just before the start of surgery.

The standardized surgical procedure for TKA was followed for all patients irrespective of the group allocation and was performed by a single surgeon under combined spinal and epidural anesthesia. A cruciate-substituting design (PFC Sigma; Depuy Synthes, Warsaw, IN, USA) was used in all patients and the patella was not resurfaced in any case. A pneumatic tourniquet was used in all patients to create a bloodless field, which was deflated after wound closure and compression dressing was applied. Tranexamic acid $1 \mathrm{~g}$ was administered intravenously before

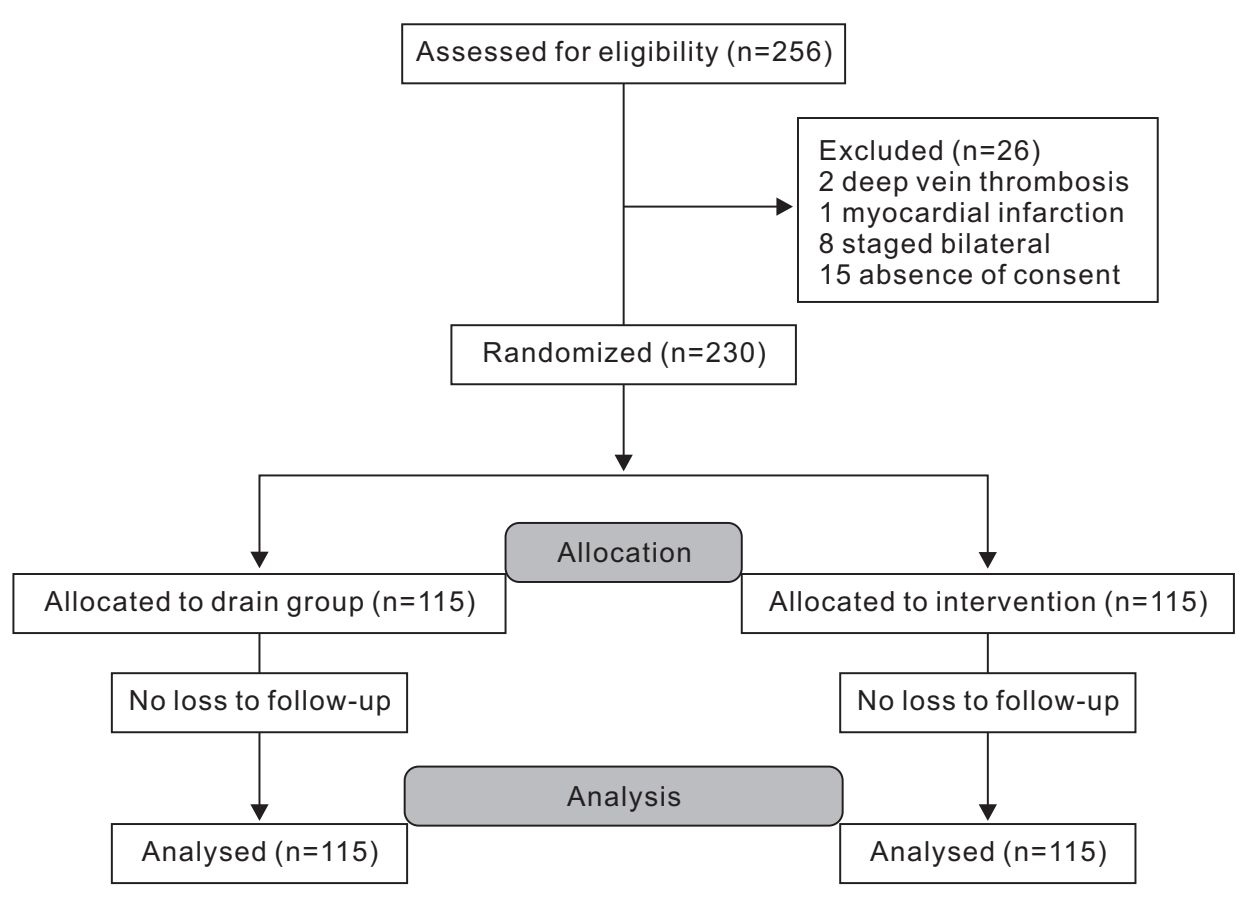

Fig. 1. Flowchart showing study design. 
induction of anesthesia and 3 hours after surgery in all patients. For DVT prophylaxis, low molecular weight heparin was used for 1 week, which was followed by oral aspirin for 6 postoperative weeks in all patients. In the drain group, a closed suction drainage was applied with no postoperative clamping and it was removed 24 hours postoperatively.

Demographic data such as age, gender, body mass index (BMI), American Society of Anesthesiologists (ASA) grade and diagnosis were collected from the hospital record files. Preoperative (on the day of admission) and postoperative (day 1 after the surgery and before discharge) serum $\mathrm{Hb}$ levels $(\mathrm{g} / \mathrm{dL}$ ) were measured and recorded. Blood was transfused in patients who had Hb below 8 $\mathrm{g} / \mathrm{dL}$ postoperatively. The total number of patients who underwent blood transfusion postoperatively and the total number of units of transfused blood in each group were recorded in the patient file. The total volume of blood loss $(\mathrm{mL})$ in each patient was calculated using Gross' formula [blood loss=preoperative blood volumex(preoperative $\mathrm{Hb}$-lowest $\mathrm{Hb}$ )/average $\mathrm{Hb}$ ] based on the maximum perioperative decrease in $\mathrm{Hb}$ and the patient's preoperative blood volume ${ }^{13)}$. Preoperative blood volume was calculated as $65 \mathrm{~mL} / \mathrm{kg}$. Average $\mathrm{Hb}$ was calculated as the mean of the preoperative $\mathrm{Hb}$ level and the lowest postoperative $\mathrm{Hb}$ level ${ }^{14)}$. Secondary outcome data on both local and systemic complications was also collected during hospital stay and at follow-up visits. Local complications looked for included superficial wound infection, hemarthrosis, DVT and periprosthetic joint infection (PJI). Similarly, systemic complications such as cardiovascular or cerebrovascular events, and pulmonary complications such as lung infection, respiratory distress or pulmonary embolism were noted. All patients were followed up for a maximum of 6 months postoperatively for this study. As part of routine clinical follow- up after TKA at our institution, all patients were called at 2 weeks, 6 weeks, 3 months and 6 months postoperatively.

The sample size at alpha 0.05 and $90 \%$ power, with prevalence of average blood loss $(1,222 \mathrm{~mL})^{4,7,14)}$ as 0.85 and expected reduction as 0.20 , was calculated as 214 . After deducting the total dropouts, the study sample was 230 . For comparison of outcomes between two groups, student's t test was used for continuous variables and chi-square test and Fisher exact test were used respectively on the basis of distribution for categorical variables. Both groups were analyzed as per intention to treat. A p-value $<0.05$ was considered statistically significant. All the statistical analysis was done with STATA ver. 13 (StataCorp LP, College Station, TX, USA) data analysis and statistical software.

\section{Results}

Demographic parameters such as gender, age, BMI, diagnosis, ASA grading and duration of hospital stay in both groups are summarized in Table 1. Similar to the mean preoperative $\mathrm{Hb}$, postoperative $\mathrm{Hb}$ in the drain group was not significantly different from the no-drain group (Table 2). The mean $\mathrm{Hb}$ levels on postoperative day 1 in the drain group and no-drain group were 9.9 \pm 1.1 (range, 7.6 to 13.3 ) and $10.1 \pm 1.1$ (range, 6.9 to 13.4), respectively, and were not significantly different between the groups $(\mathrm{p}=0.16)$. The mean $\mathrm{Hb}$ reduction postoperatively in the drain group (3.24 g/dL) and no-drain group (3.54 g/dL) was also not significantly different $(\mathrm{p}=0.33)$.

No statistically significant difference was found in the blood transfusion rates and total units of blood transfused between two groups (Table 2). Two patients in no-drain group received blood transfusion at the time of readmission after day 1 ( 2 units) and

Table 1. Comparison of Demographic Data between the Two Study Groups

\begin{tabular}{|c|c|c|c|}
\hline Parameter & Drain group $(n=115)$ & No-drain group $(\mathrm{n}=115)$ & p-value \\
\hline \multicolumn{4}{|l|}{ Gender (\%) } \\
\hline Male & $26(22.5)$ & $36(31)$ & 0.18 \\
\hline Female & $89(77.5)$ & $79(65)$ & \\
\hline Age (yr) & $64.0 \pm 7.8(62.6-65.5)$ & $65.0 \pm 8.7(63.5-66.7)$ & 0.35 \\
\hline Body mass index $\left(\mathrm{kg} / \mathrm{m}^{2}\right)$ & $26.7 \pm 5.1(25.7-27.6)$ & $29.3 \pm 3.8(28.5-30)$ & $<0.01$ \\
\hline \multicolumn{4}{|l|}{ Diagnosis (\%) } \\
\hline Osteoarthritis & $110(95.5)$ & $114(99)$ & 0.21 \\
\hline Rheumatoid arthritis & $5(4.5)$ & $1(1)$ & \\
\hline ASA grade II (\%) & 82 & 89.5 & 0.22 \\
\hline Duration of hospital stay (day) & $6.3 \pm 1(6.1-6.4)$ & $6.4 \pm 1.1(6.2-6.6)$ & 0.47 \\
\hline
\end{tabular}

Values are presented as mean \pm standard deviation ( $95 \%$ confidence interval). $\mathrm{p}<0.05$ considered statistically significant.

ASA: American Society of Anesthesiologists. 
Table 2. Comparison of Hemoglobin (Hb) Levels, Blood Loss and Transfusion Rates between the Two Study Groups

\begin{tabular}{lccc}
\hline \multicolumn{1}{c}{ Parameter } & Drain group $(\mathrm{n}=115)$ & No-drain group $(\mathrm{n}=115)$ & $\mathrm{p}$-value \\
\hline Preoperative $\mathrm{Hb}(\mathrm{g} / \mathrm{dL})$ & $12.2 \pm 1.2(11.9-12.4)$ & $12.3 \pm 1.4(12.0-12.6)$ & 0.35 \\
Postoperative $\mathrm{Hb}(\mathrm{g} / \mathrm{dL})$ & $9.0 \pm 1.0(8.8-9.2)$ & $9.2 \pm 1.2(8.9-9.4)$ & 0.38 \\
Lowest $\mathrm{Hb}(\mathrm{g} / \mathrm{dL})$ & $9.0 \pm 1.0(8.8-9.2)$ & $436.9 \pm 83.3$ & 0.33 \\
Calculated blood loss $(\mathrm{mL})$ & $448.5 \pm 96.3$ & $30(26)$ & 0.33 \\
No. of patients transfused $(\%)$ & $31(27)$ & 37 & 0.88 \\
Unit of blood transfused $(\mathrm{n})$ & 40 & 0.52 \\
\hline
\end{tabular}

Values are presented as mean \pm standard deviation ( $95 \%$ confidence interval). $\mathrm{p}<0.05$ considered statistically significant.

Table 3. Systemic and Local Complications in the Two Study Groups

\begin{tabular}{lcc}
\hline \multicolumn{1}{c}{ Complication } & $\begin{array}{c}\text { Drain } \\
\text { group } \\
(\mathrm{n}=115)\end{array}$ & $\begin{array}{c}\text { No-drain } \\
\text { group } \\
(\mathrm{n}=115)\end{array}$ \\
\hline Systemic & 2 & 0 \\
Mortality & 0 & 1 \\
CVA (seizure) & 1 & 3 \\
Cardiovascular event (MI, angina, and AF) & 1 & 0 \\
Pulmonary infection (bilateral pneumonia) & 1 & 0 \\
Respiratory distress & 0 & 2 \\
Fever & $5(4.5)$ & $6(5)$ \\
Total (\%) & & \\
Local & 3 & 0 \\
Superficial wound infection & 1 & 0 \\
Periprosthetic joint infection & 1 & 0 \\
Periprosthetic fracture & 0 & 1 \\
Revision surgery & $5(4.5)$ & $1(1)$ \\
Total (\%) & & \\
\hline
\end{tabular}

CVA: cerebrovascular accident, MI: myocardial infarction, AF: atrial fibrillation.

day 5 (1 unit) after discharge, respectively. There was no significant difference in local $(\mathrm{p}=0.09)$ and systemic $(\mathrm{p}=0.64)$ complications between the two groups (Table 3 ). None of the patients in both groups had DVT or pulmonary embolism. There were total 9 readmissions, 6 in the drain group and 3 in the no-drain group. The reasons for readmissions in the drain group included superficial wound infection (3 patients) treated with local debridement and resuturing, PJI (1 patient) treated with debridement and insert change, angina on exertion (1 patient) and periprosthetic fracture (1 patient). In the no-drain group, one patient each was readmitted for anemia, fever and knee instability (treated with revision surgery). Two patients in the drain group died, one due to septicemia and one due to bilateral pneumonia. No mortality occurred in the no-drain group.

\section{Discussion}

In this prospective randomized study, use of closed suction drains in simultaneous bilateral TKAs did not result in significant increase in blood loss, reduction in $\mathrm{Hb}$ or increased transfusion rates postoperatively when compared to patients where drains were not used. Although several investigators have studied the effect of suction drains on blood loss and transfusion rates after TKA, most of these were conducted in patients undergoing unilateral or staged bilateral TKA.

A recent retrospective study by Demirkale et al. ${ }^{4)}$, which analyzed postoperative reduction in $\mathrm{Hb}$ and blood transfusion rates, reported that reduction in $\mathrm{Hb}$ and the need for transfusion postoperatively was significantly lower in the non-drainage group when compared to the drainage group. This finding is contrary to that of the current study and is primarily due to difference in the study design. First, several parameters were different between the two groups including the type of tourniquet, exsanguination method, technique of hemostasis and the time of tourniquet release. In the current study, all parameters were similar between the two study groups including the surgical, exsanguination, hemostasis and wound closure technique, and the use of drain was the only parameter that varied between groups. Second, their retrospective study included cases treated by different surgeons where variation in surgical technique may have resulted in significant difference in blood loss between the two study groups. In contrast, the current study included cases treated by a single surgeon at a single institution.

Several studies have suggested that drains are not required in an uncomplicated primary TKA ${ }^{15-18)}$. However, some investigators advocate the continued use of drains in order to reduce tissue ecchymosis, minimize local hematoma and wound soakage and need for frequent change of dressing ${ }^{19-24)}$. Our study did not show any significant difference in complication rates between drain and no-drain groups. Demirkale et al. ${ }^{4)}$ in their retrospective study reported significantly lower infection rate 
in the non-drainage group. In contrast, our study did not show any statistically significant difference in the infection rate (both superficial wound and deep periprosthetic infection) between the two groups $(\mathrm{p}=0.12)$ although the incidence of infection rate was higher in the drain group $(n=4)$ compared to the no-drain group $(n=0)$ (Table 3$)$. This difference in the infection rate was probably due to the higher number of knees $(n=946)$ in the study by Demirkale et al. ${ }^{4)}$ compared to the current study ( $\left.n=230\right)$. Furthermore, differences in the type of tourniquet, exsanguination method, technique of hemostasis, the time of tourniquet release and surgeon technique between the two groups in the study by Demirkale et al. ${ }^{4)}$ may also have resulted in the difference in infection rates between the two groups.

The primary concern in patients undergoing simultaneous bilateral TKA is excessive blood loss and complications arising from postoperative reduction in $\mathrm{Hb}$. This may increase the morbidity and risk associated with simultaneous bilateral TKAs. The use of autologous reinfusion drains has been suggested in order to minimize blood loss and maintain postoperative $\mathrm{Hb}$ level. However, the efficacy and cost-effectiveness of autologous reinfusion drains over no drains or simple closed suction drains in simultaneous bilateral TKAs are unclear. Horstmann et al. ${ }^{25)}$, in a randomized controlled trial on unilateral TKAs, reported that autologous reinfusion drains result in higher postoperative $\mathrm{Hb}$ levels and less blood loss. In contrast, Al-Zahid and Davies ${ }^{10)}$, in their study comparing closed suction drains, reinfusion drains and no drains, reported no significant difference in reduction of postoperative $\mathrm{Hb}$ level and transfusion rates among the 3 groups.

One of the limitations of our study was to base the decision to transfuse a patient postoperatively using the standard practice of an $\mathrm{Hb}$ cut-off level of less than $8 \mathrm{~g} / \mathrm{dL}^{26}$. However, recent literature has recommended taking into consideration clinical symptoms, tissue and blood oxygenation apart from $\mathrm{Hb}$ level to achieve a more patient-specific, "physiological" approach to postoperative blood transfusion after $\mathrm{TKA}^{26,27)}$. Second, drains used in the drain group of our study were not clamped postoperatively. Postoperative clamping of the drain has been reported to reduce postoperative blood volume drained and reduction in $\mathrm{Hb}^{28)}$ and our decision not to clamp drains postoperatively may have influenced the volume of blood loss and reduction in $\mathrm{Hb}$ in the drain group. Lastly, the mean BMI was significantly higher in the no-drain group compared to the drain group in our study, which may have affected postoperative blood loss and reduction in $\mathrm{Hb}^{29,30)}$

\section{Conclusions}

In patients undergoing simultaneous bilateral TKA, use of drains does not lead to increased postoperative reduction in $\mathrm{Hb}$, blood loss or blood transfusion rates when compared to patients without drain. Non-drainage in simultaneous bilateral knee replacements does not offer an advantage over drainage with respect to conserving blood in simultaneous bilateral TKA.

\section{Conflict of Interest}

No potential conflict of interest relevant to this article was reported.

\section{Acknowledgements}

The authors thank Ms. Kriti Jain for her contribution to preparation of the manuscript.

\section{References}

1. Alexander JW, Korelitz J, Alexander NS. Prevention of wound infections: a case for closed suction drainage to remove wound fluids deficient in opsonic proteins. Am J Surg. 1976;132:59-63.

2. Maitland AI, Mathieson AJ. Suction drainage: a study in wound healing. Br J Surg. 1970;57:193-7.

3. Parker MJ, Roberts CP, Hay D. Closed suction drainage for hip and knee arthroplasty: a meta-analysis. J Bone Joint Surg Am. 2004;86:1146-52.

4. Demirkale I, Tecimel O, Sesen H, Kilicarslan K, Altay M, Dogan M. Nondrainage decreases blood transfusion need and infection rate in bilateral total knee arthroplasty. J Arthroplasty. 2014;29:993-7.

5. Zhang QD, Guo WS, Zhang Q, Liu ZH, Cheng LM, Li ZR. Comparison between closed suction drainage and nondrainage in total knee arthroplasty: a meta-analysis. J Arthroplasty. 2011;26:1265-72.

6. Majeed H, Bishnoi A, Yallupa S, Howard P. Blood transfusion after total knee arthroplasty: comparison of drainage versus non-drainage. J Hematol Thromb Dis 2013:1:114.

7. Cushner FD, Scott WN, Scuderi G, Hill K, Insall JN. Blood loss and transfusion rates in bilateral total knee arthroplasty. J Knee Surg. 2005;18:102-7.

8. Sehat KR, Evans R, Newman JH. How much blood is really lost in total knee arthroplasty? Correct blood loss manage- 
ment should take hidden loss into account. Knee. 2000;7: 151-5.

9. Husted H. A low hemoglobin transfusion trigger is not dangerous: arguments in favor. In: Baldini A, Caldora P, eds. Perioperative medical management for total joint arthroplasty: how to control hemostasis, pain and infection. 1st ed. Cham: Springer; 2015. p73-4.

10. Al-Zahid S, Davies AP. Closed suction drains, reinfusion drains or no drains in primary total knee replacement? Ann R Coll Surg Engl. 2012;94:347-50.

11. Li C, Nijat A, Askar M. No clear advantage to use of wound drains after unilateral total knee arthroplasty: a prospective randomized, controlled trial. J Arthroplasty. 2011;26:519-22.

12. Schulz KF, Altman DG, Moher D; CONSORT Group. CONSORT 2010 Statement: Updated guidelines for reporting parallel group randomised trials. J Clin Epidemiol. 2010;63: 834-40.

13. Gross JB. Estimating allowable blood loss: corrected for dilution. Anesthesiology. 1983;58:277-80.

14. Levy O, Martinowitz U, Oran A, Tauber C, Horoszowski H. The use of fibrin tissue adhesive to reduce blood loss and the need for blood transfusion after total knee arthroplasty. A prospective, randomized, multicenter study. J Bone Joint Surg Am. 1999;81:1580-8.

15. Kumar S, Penematsa S, Parekh S. Are drains required following a routine primary total joint arthroplasty? Int Orthop. 2007;31:593-6.

16. Niskanen RO, Korkala OL, Haapala J, Kuokkanen HO, Kaukonen JP, Salo SA. Drainage is of no use in primary uncomplicated cemented hip and knee arthroplasty for osteoarthritis: a prospective randomized study. J Arthroplasty. 2000;15:567-9.

17. Fan Y, Liu Y, Lin J, Chang X, Wang W, Weng XS, Qiu GX. Drainage does not promote post-operative rehabilitation after bilateral total knee arthroplasties compared with nondrainage. Chin Med Sci J. 2013;28:206-10.

18. Widman J, Jacobsson H, Larsson SA, Isacson J. No effect of drains on the postoperative hematoma volume in hip replacement surgery: a randomized study using scintigraphy. Acta Orthop Scand. 2002;73:625-9.

19. Holt BT, Parks NL, Engh GA, Lawrence JM. Comparison of closed-suction drainage and no drainage after primary total knee arthroplasty. Orthopedics. 1997;20:1121-4.
20. Kim YH, Cho SH, Kim RS. Drainage versus nondrainage in simultaneous bilateral total knee arthroplasties. Clin Orthop Relat Res. 1998;(347):188-93.

21. Jenny JY, Boeri C, Lafare $S$. No drainage does not increase complication risk after total knee prosthesis implantation: a prospective, comparative, randomized study. Knee Surg Sports Traumatol Arthrosc. 2001;9:299-301.

22. Ovadia D, Luger E, Bickels J, Menachem A, Dekel S. Efficacy of closed wound drainage after total joint arthroplasty: a prospective randomized study. J Arthroplasty. 1997;12:317-21.

23. Li N, Liu M, Wang D, He M, Xia L. Comparison of complications in one-stage bilateral total knee arthroplasty with and without drainage. J Orthop Surg Res. 2015;10:3.

24. Zhang QD, Guo WS, Zhang Q, Liu ZH, Cheng LM, Li ZR. Comparison between closed suction drainage and nondrainage in total knee arthroplasty: a meta-analysis. J Arthroplasty. 2011;26:1265-72.

25. Horstmann W, Kuipers B, Ohanis D, Slappendel R, Kollen B, Verheyen C. Autologous re-transfusion drain compared with no drain in total knee arthroplasty: a randomised controlled trial. Blood Transfus. 2014;12 Suppl 1:s176-81.

26. Vuille-Lessard E, Boudreault D, Girard F, Ruel M, Chagnon M, Hardy JF. Red blood cell transfusion practice in elective orthopedic surgery: a multicenter cohort study. Transfusion. 2010;50:2117-24.

27. Gentilini G, Ringressi A. A low hemoglobin transfusion trigger is not dangerous: arguments against. In: Baldini A, Caldora P, eds. Perioperative medical management for total joint arthroplasty: how to control hemostasis, pain and infection. 1st ed. Cham: Springer; 2015. p79-84.

28. Pornrattanamaneewong C, Narkbunnam R, Siriwattanasakul P, Chareancholvanich K. Three-hour interval drain clamping reduces postoperative bleeding in total knee arthroplasty: a prospective randomized controlled trial. Arch Orthop Trauma Surg. 2012;132:1059-63.

29. Frisch NB, Wessell NM, Charters MA, Yu S, Jeffries JJ, Silverton CD. Predictors and complications of blood transfusion in total hip and knee arthroplasty. J Arthroplasty. 2014;29(9 Suppl):189-92.

30. Hrnack SA, Skeen N, Xu T, Rosenstein AD. Correlation of body mass index and blood loss during total knee and total hip arthroplasty. Am J Orthop (Belle Mead NJ). 2012;41:467-71. 